\title{
A systematic review of international guidelines and recommendations for the genetic screening, diagnosis, genetic counseling, and treatment of BRCA-mutated breast cancer
}

This article was published in the following Dove Medical Press journal: Cancer Management and Research

\author{
Carol Forbes' \\ Debra Fayter ${ }^{\prime}$ \\ Shelley de Kock ${ }^{2}$ \\ Ruben GW Quek ${ }^{3}$ \\ 'Department of Reviews, Kleijnen \\ Systematic Reviews Ltd, Escrick, \\ York YOI 9 6FD, UK; ${ }^{2}$ Department \\ of Information, Kleijnen Systematic \\ Reviews Ltd, Escrick, York YOI9 6FD, \\ UK; ${ }^{3}$ Health Economics and Outcomes \\ Research, Pfizer Inc., San Francisco, \\ CA 94I05, USA
}

Purpose: To conduct a systematic review of international guidelines on screening and management of patients with $B R C A$-mutated breast cancer (BC).

Methods: Major electronic databases (MEDLINE and Embase; $\mathrm{N}=8$ ) and gray literature sources were searched (January 2007 to February 2018). Latest guideline recommendations on genetic screening, counseling, and $\mathrm{BC}$ treatment of $B R C A$ mutation carriers were summarized. Guidelines specific to germline $B R C A(\mathrm{~g} B R C A)$ mutation were captured where available.

Results: A total of 3,775 records were retrieved and 32 guidelines were included; Europe $(n=16)$, USA $(n=11)$, Canada $(n=3)$, Australia $(n=1)$, and Japan $(n=1)$ were included. Across and within guidelines, genetic counseling was recommended at multiple points in the care pathway, though the format was not always clearly defined. US guidelines emphasized that $B R C A$ mutation testing should occur after specialized genetic counseling; other European guidelines are less prescriptive. $B R C A$ testing eligibility criteria differed, with some guidelines being less restrictive; US National Comprehensive Cancer Network (NCCN) BC guidelines specified that HER2-negative $\mathrm{BC}$ patients eligible for single-agent therapy are eligible for $\mathrm{g} B R C A$ testing. Fast-track $B R C A$ testing is recommended in the Netherlands if treatment choice will affect survival, but in the UK only as part of clinical trials. More recent European (European School of Oncology-European Society for Medical Oncology 3rd International Consensus Guidelines for Breast Cancer in Young Women 2017, Arbeitsgemeinschaft Gynäkologische Onkologie 2017 in Germany) and US (NCCN) guidelines have updated recommendations regarding $\mathrm{g} B R C A$-targeted poly(ADP-ribose) polymerase (PARP) inhibitor therapy in BC.

Conclusion: Regional and organizational guidelines differ for genetic screening, counseling, and treatment of patients with BRCA-mutated BC. Guideline harmonization would optimize identification and management of these patients.

Keywords: $B R C A 1, B R C A 2$, guidelines, systematic review, chemotherapy, PARP inhibitor

\section{Introduction}

Genetic predisposition to breast cancer $(\mathrm{BC})$ may be associated with mutation in a particular gene or set of genes, including the key tumor-suppressor genes $B R C A 1 / 2 .{ }^{1} B R C A$ mutation may be inherited (germline $B R C A$ [gBRCA]) or arise de novo as a result of combinatorial genetic and environmental factors (somatic). ${ }^{1}$ Specific population subgroups have been identified as having a higher proportion of individuals who carry $B R C A$ mutations, including those who have been diagnosed with triple-negative breast cancer (TNBC) and those from different ethnic groups, including black populations and those of Ashkenazi Jewish
Correspondence: Carol Forbes Department of Reviews, Kleijnen Systematic Reviews Ltd, Unit 6, Escrick Business Park, Riccall Road, York YOI9 6FD, UK

Tel +44 I904 727980

Fax +441904 720429

Email carol@systematic-reviews.com 
heritage..$^{2-4}$ The majority of multiple $\mathrm{BC}$ cases within families, including male $\mathrm{BC}$, are due to $\mathrm{g} B R C A$ mutations. ${ }^{5} \mathrm{~g} B R C A$ mutation carriers have an increased lifetime risk of developing BC. ${ }^{5}$

Identification of $B R C A$ mutation through genetic screening offers the opportunity to increase monitoring and surveillance of people for breast and other cancers, in addition to offering them prophylactic, risk-reducing interventions. Which individuals are eligible to receive $B R C A$ screening varies across countries, with some testing strategies being more inclusive than others. The uptake of $B R C A$ testing has also been shown to vary across populations, with genetic counseling suggested as having an influence on this. ${ }^{6} \mathrm{Mul}-$ tiple Phase III randomized controlled trials have recently been published showing treatments that benefit patients with advanced $\mathrm{BC}(\mathrm{ABC})$ and $\mathrm{g} B R C A$ mutation; ${ }^{7-9}$ specifically, platinum-based regimens and PARP inhibitors are offering new $\mathrm{g} B R C A$ mutation-targeted approaches in $\mathrm{ABC} .{ }^{10}$

Prior research across international healthcare systems has suggested gaps regarding the implementation of populationbased $B R C A$ screening and the need to improve healthcare providers' knowledge about existing $B R C A$ screening recommendations. ${ }^{11,12}$ Strategies including specific training and the harmonization of guidelines have been recommended to increase awareness of $B R C A$ screening programs in $\mathrm{BC}$ to enhance the guideline concordance in clinical practice. ${ }^{12,13}$

Given recent developments in the management of $B R C A$ mutated $\mathrm{BC}$ and the importance of understanding the differences in recommendations globally, a systematic literature review on the latest international guidelines was conducted to summarize recommendations regarding genetic screening, diagnosis, genetic counseling, and treatment.

\section{Methods}

This systematic review was carried out in accordance with a prespecified protocol (available from the authors on request) and methodologies recommended by the Cochrane collaboration ${ }^{14}$ and the Centre for Reviews and Dissemination. ${ }^{15}$ Guidelines reporting recommendations on genetic screening, diagnosis, genetic counseling, and treatment of $\mathrm{BC}$ with $B R C A$ mutations were searched for from Europe (France, Germany, Ireland, Italy, the Netherlands, Spain, UK), North America (USA, Canada), Australia, Israel, Japan, Russia, and South Korea. Study inclusion was not limited by language, but only data that were publicly available and reported from 1 January 2007-7 February 2018 were eligible for inclusion in the review.

Extensive literature searches were undertaken and included 8 electronic databases; 17 guideline, health technology, and other resources; and 7 conference abstract collections in the geographies of interest (Supplementary material).
Two reviewers independently screened and selected guidelines for inclusion in the review, with discrepancies resolved through consensus with a third reviewer. Data were extracted from the most recent version of each included guideline, and the quality of the guidelines was assessed using the AGREE II tool. ${ }^{16}$ A narrative summary of the guideline recommendations with accompanying evidence grades (where available) was presented according to the stage of patient care (screening, counseling, risk reduction, treatment, patient management/care, and recommendations for further research) and the target population of interest (patients with germline-specified $B R C A$ mutation, men, black/African, Ashkenazi Jews, locally advanced/metastatic $B R C A$ TNBC, and locally advanced/metastatic $B R C A$ HR-positive/HER2negative $\mathrm{BC}$ ) wherever specified.

\section{Results \\ Guideline selection process}

A total of 3,775 titles and abstracts were retrieved from the literature searches of databases and hand-searching. From these, full papers were obtained for 114 citations. After further review, a total of 82 papers were excluded from the review. The remaining 32 papers, which are included in this review, represented 32 guidelines and were published between $2010^{17}$ and $2018,{ }^{18}$ the majority (70\%) within the last 3 years $(2015$ onward). Most were from Europe (16 guidelines) and North America (14 guidelines). Additional guidelines were identified in Australia (one guideline) ${ }^{19}$ and Japan (one guideline). ${ }^{20} \mathrm{~A}$ summary of the guideline selection process according to the PRISMA is given in Figure 1, and an overview summary of the included guidelines is shown in Table 1 .

\section{Summary of quality of guidelines}

All 32 included guidelines were assessed using the AGREE II tool (Supplementary material). However, in many cases, poor reporting of the guidelines hampered the AGREE II assessment as it was impossible to distinguish whether guidelines were of insufficient quality or whether the methodologies were just poorly reported. In some cases, methodologies were described elsewhere, including earlier versions of guidelines, and could not be easily tracked through multiple revisions. ${ }^{21,22}$ Where relevant, additional sources that provided information on the guideline methods were consulted and incorporated in the AGREE II assessments. ${ }^{23,24}$

Taking account of the potential limitations of the guidelines identified in the AGREE II assessment, overall eight of the guidelines ${ }^{4,19,23-28}$ were recommended for use specifically in patients with $B R C A$-mutated BC. A further eight guidelines ${ }^{3,21,22,29-33}$ were also recommended for use, but would benefit from changes to 


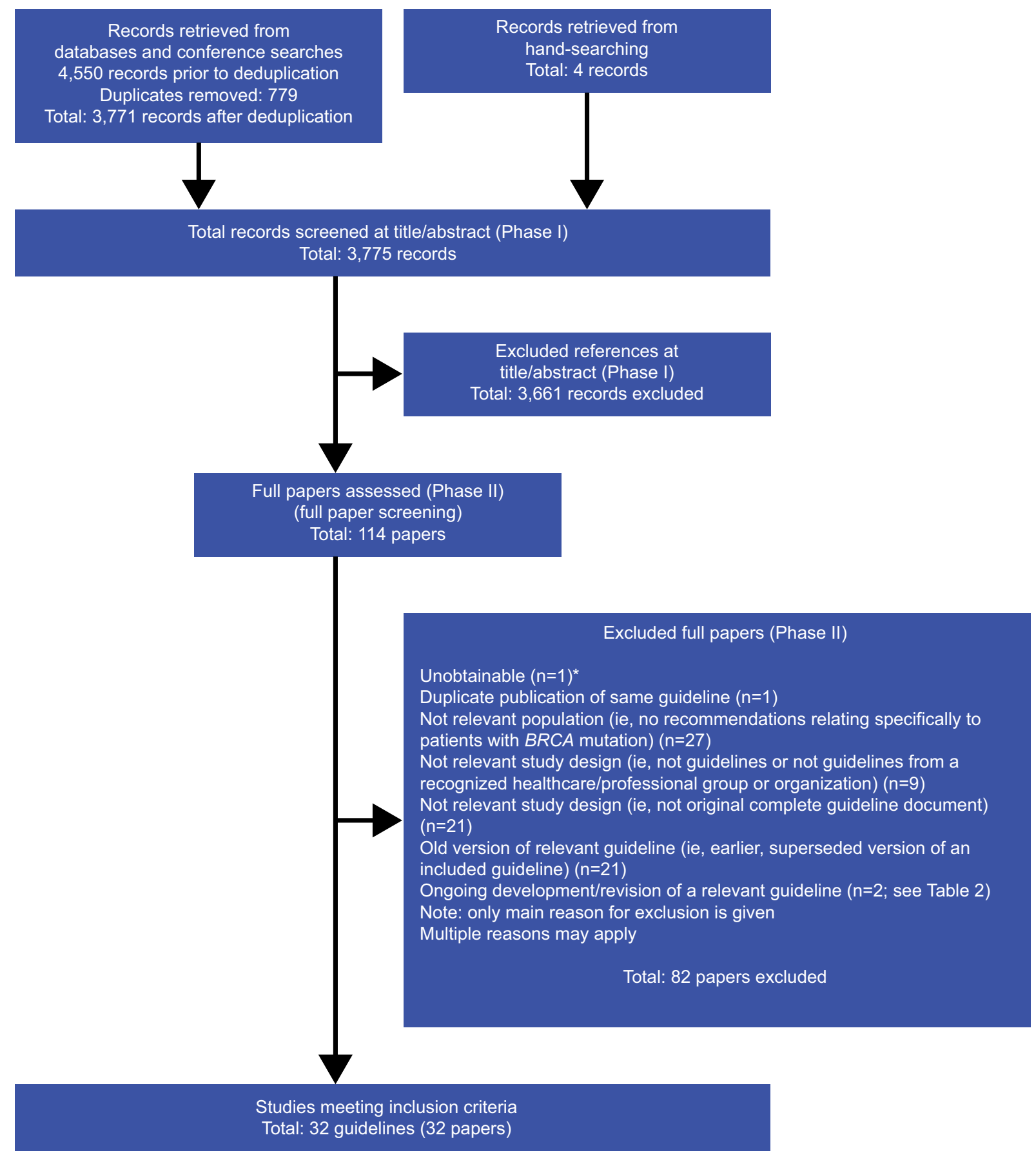

Figure I PRISMA flow chart.

Notes: *Unobtainable paper - not available through online sources or British Library. This paper is published in 2012 and only has two authors, with no mention of a recognized group or guideline/cancer organization. The title suggests it relates to breast cancer in general (no specific mention of BRCA in the keywords, title, or abstract). At full paper screening to reduce the risk of missing relevant BRCA recommendations, we have screened all general breast cancer guidelines. However, it is unlikely that this paper will be relevant and so its "unobtainable" status is unlikely to affect the findings of the review.

their methodologies or reporting in order to tailor them for use in patients with $\mathrm{g} B R C A$ and $B R C A$-mutated $\mathrm{BC}$. Therefore, there were issues (eg, based on out-of-date evidence, a lack of clear recommendation statements, and/or poorly described methodologies) in half of the 32 included guidelines which suggested that they may be at risk of bias and potentially not appropriate for use specifically for $B R C A$ patients.

\section{Recommendations for genetic counseling} Fifteen relevant guidelines were identified as reporting recommendations on genetic counseling (Supplementary material) and were in general agreement about the importance of genetic counseling before and after $B R C A$ testing, including prior to $\mathrm{BC}$ risk-reduction procedures (eg, mastectomy, oophorectomy). Eight were from Europe. . $^{4,21,23,26,29,34} \mathrm{Six}$ were 


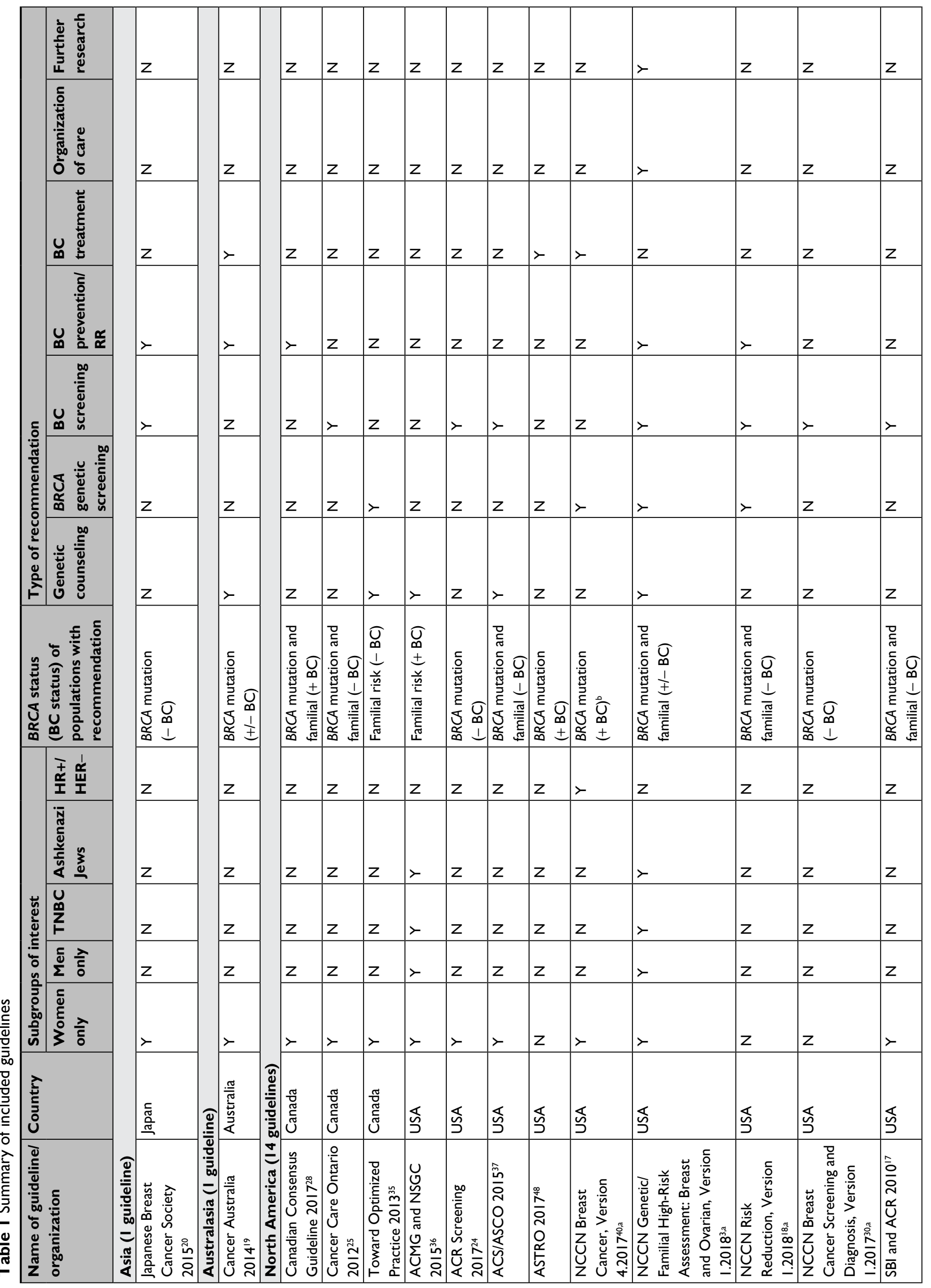




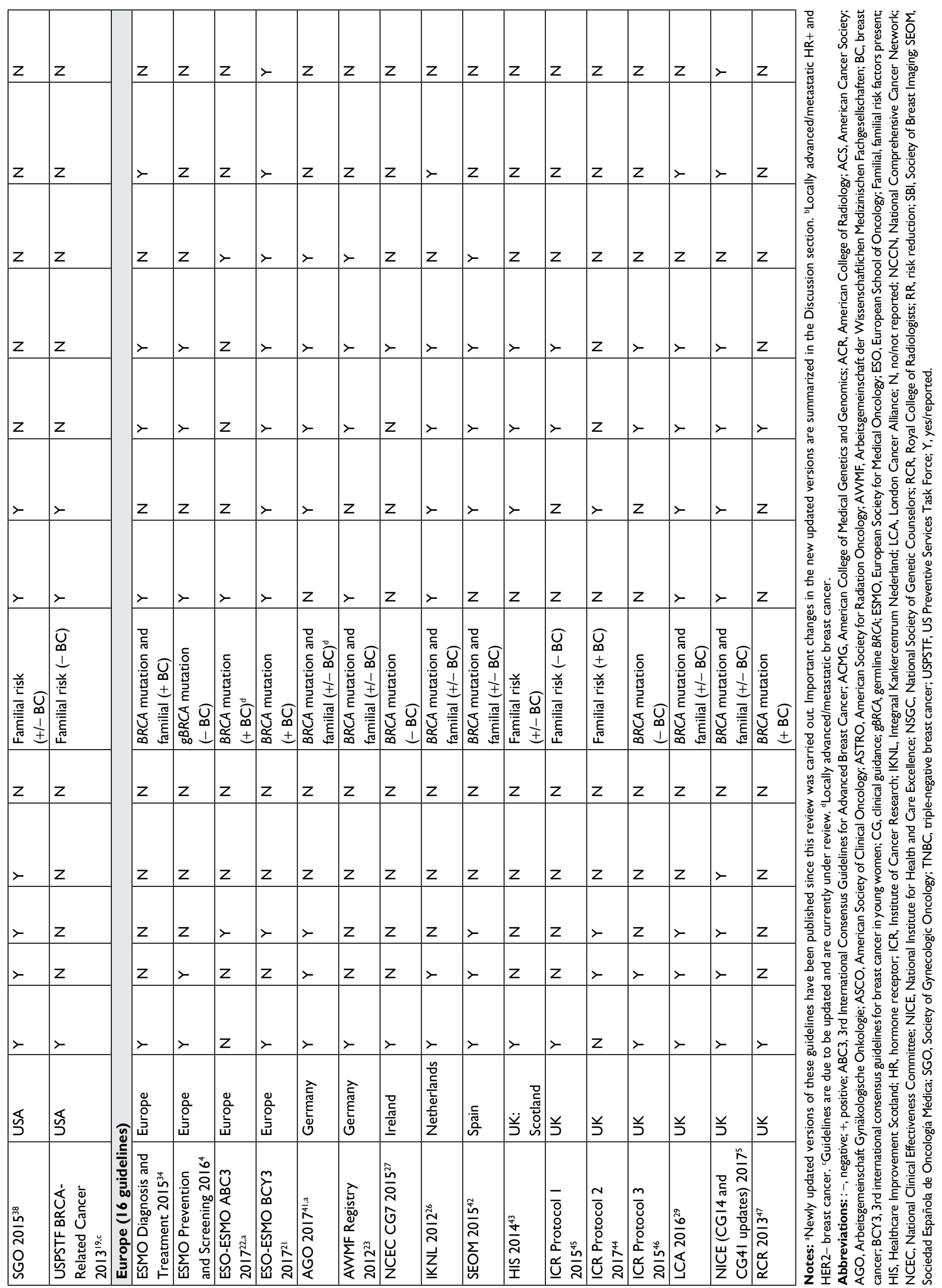


from North America ${ }^{3,35-39}$ and one from Australia. ${ }^{19}$ Recommendations for genetic counseling were made for three main populations: those with a familial risk of $\mathrm{BC},{ }^{3,23,38} B R C A$ carriers, and those who have $\mathrm{BC}$ and/or a personal history of BC. ${ }^{3}$ A number of guidelines across the USA, Canada, and Europe agreed that predictive genetic testing should not be offered without adequate genetic counseling., ${ }^{3,5,29}$ Recommendations from the US National Comprehensive Cancer Network (NCCN) Genetic/Familial High-Risk Assessment: Breast and Ovarian, Version 1.2018 guidelines $^{3}$ focused on the content and structure of genetic counseling sessions for those who had already been identified as carriers of a $B R C A$ mutation and included providing information to patients regarding prophylactic interventions such as mastectomy, oophorectomy, and drug therapies, as well as advice regarding reproductive health. Similar recommendations about the content of genetic counseling sessions were also outlined in the European Society for Medical Oncology (ESMO) Prevention and Screening 2016 guidelines ${ }^{4}$ in Europe and addressed issues of quality of life and the psychosocial impact of risk-reducing interventions.

\section{Recommendations relating to $B R C A$ testing}

Four North American ${ }^{3,35,38,40}$ and nine European ${ }^{5,21,22,26,29,41-44}$ guidelines recommended testing for $B R C A$ mutations. Table 2 summarizes the main recommendations of the included guidelines.

For individuals with BC, the Netherlands Integraal Kankercentrum Nederland (IKNL) guidelines recommended that urgent DNA testing for a $B R C A 1 / 2$ mutation be considered if it influenced the woman's choice for primary cancer treatment with regard to survival consequences. ${ }^{26}$ Both the UK London Cancer Alliance (LCA) $2016^{29}$ and the US NCCN Genetic/Familial High-Risk Assessment: Breast and Ovarian, Version 1.2018 guidelines emphasized that genetic testing should be undertaken only after consultation and counseling by a genetics service and further personalized risk assessment. Furthermore, the $\mathrm{NCCN}^{3}$ guideline also stressed that genetic testing should only be considered for high-risk individuals if it would affect the medical management of the tested individual and/or the individual's at-risk family members. On the other hand, the UK National Institute for Health and Care Excellence (NICE) CG164 (CG14 and CG41 updates) $2017^{5}$ guideline made recommendations regarding $B R C A$ testing in general, but recommended that the use of fast-track genetic testing within 4 weeks of $B C$ diagnosis should only be offered as part of a clinical trial. Both the US NCCN Genetic/Familial High-Risk Assessment: Breast and Ovarian, Version 1.2018 3 and the NICE CG164 (CG14 and CG41 updates) $2017^{5}$ guidelines also specified certain proce- dures for undertaking genetic testing (full sequencing, testing in individuals who had received an allogeneic bone transplant, and the use of searchable electronic databases).

Few guidelines provided recommendations on the specific type of $B R C A$ test, and guidelines usually avoided mentioning any brand by name. However, the UK NICE guidelines ${ }^{5}$ recommended that "a search/screen for a mutation in a gene (such as BRCA1, BRCA2, or TP53) should aim for as close to $100 \%$ sensitivity as possible for detecting coding alterations and the whole gene(s) should be searched." The US NCCN Genetic/Familial High-Risk Assessment: Breast and Ovarian, Version $1.2018^{3}$ guideline emphasized the need for "comprehensive genetic testing", which included full $B R C A 1 / 2$ sequencing and testing for large genomic rearrangements. The European School of Oncology (ESO)-ESMO 3rd international consensus guidelines for breast cancer in young women (BCY3) $2017^{21}$ recommended that a multigene panel test be used and that practice should be guided by high-quality national or international guidelines, as commercially available multigene panels include different panels of genes.

Nine guidelines, three from North America ${ }^{3,35,38}$ and six from Europe $\mathrm{s}^{5,6,29,41,42,44}$ made specific recommendations about genetic screening for $B R C A$ mutation in men. All guidelines agreed that in unaffected individuals, the presence of male $B C$ in the family warranted further risk assessment, genetic counseling, and possibly genetic testing. With respect to $B R C A$ testing in other groups, there were no recommendations specifically relating to the black/African population, although women eligible for single-agent therapy for recurrent or metastatic HER2negative $\mathrm{BC}$ were eligible for $\mathrm{g} B R C A 1 / 2$ testing according to NCCN Breast Cancer, Version 4.2017. ${ }^{40}$ The NCCN Genetic/ Familial High-Risk Assessment: Breast and Ovarian, Version 1.2018 also recommended $B R C A$ testing where "BRCA1/2 pathogenic mutation was detected by tumor profiling on any tumor type in the absence of germline mutation analysis."

\section{Recommendations relating to $B C$ screening}

Twenty-one guidelines made recommendations regarding $\mathrm{BC}$ screening in individuals at high risk of $\mathrm{BC}$ based on family history or a known $B R C A 1 / 2$ mutation. One of these was from Asia, ${ }^{20}$ six were from North America, ${ }^{3,17,24,25,30,37}$ and 13 were from Europe. . $, 5,21,23,26,29,34,41-43,45-47$

Many guidelines recommended a multimodal screening approach. Six guidelines recommended a combination of annual MRI and annual mammography for women with familial risk or $B R C A$ mutation and a history of $\mathrm{BC}$. $3,5,29,34,37,47$

The ESMO Prevention and Screening $2016^{4}$ guidelines stated that $\mathrm{g} B R C A$ patients should be encouraged to 


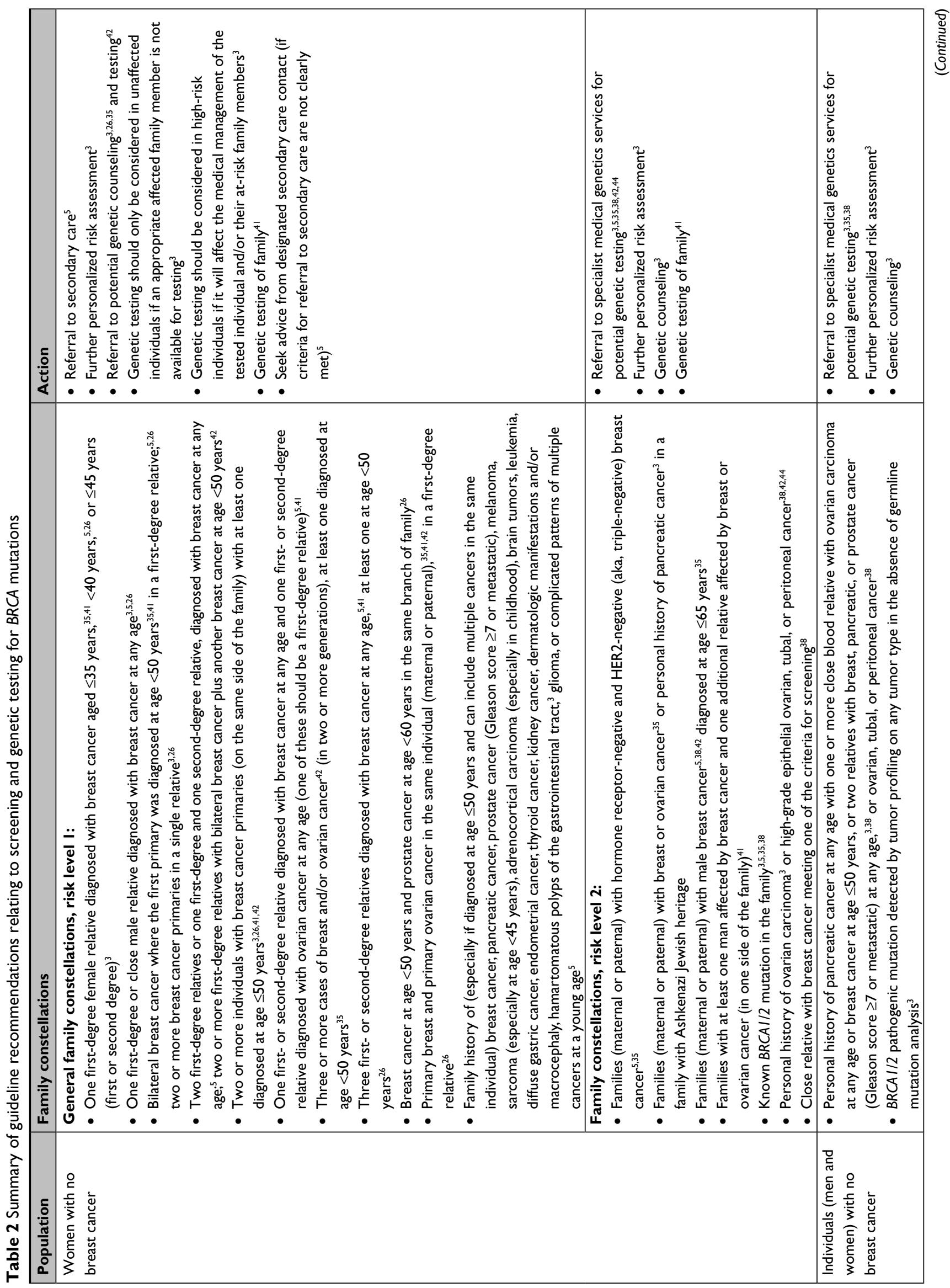




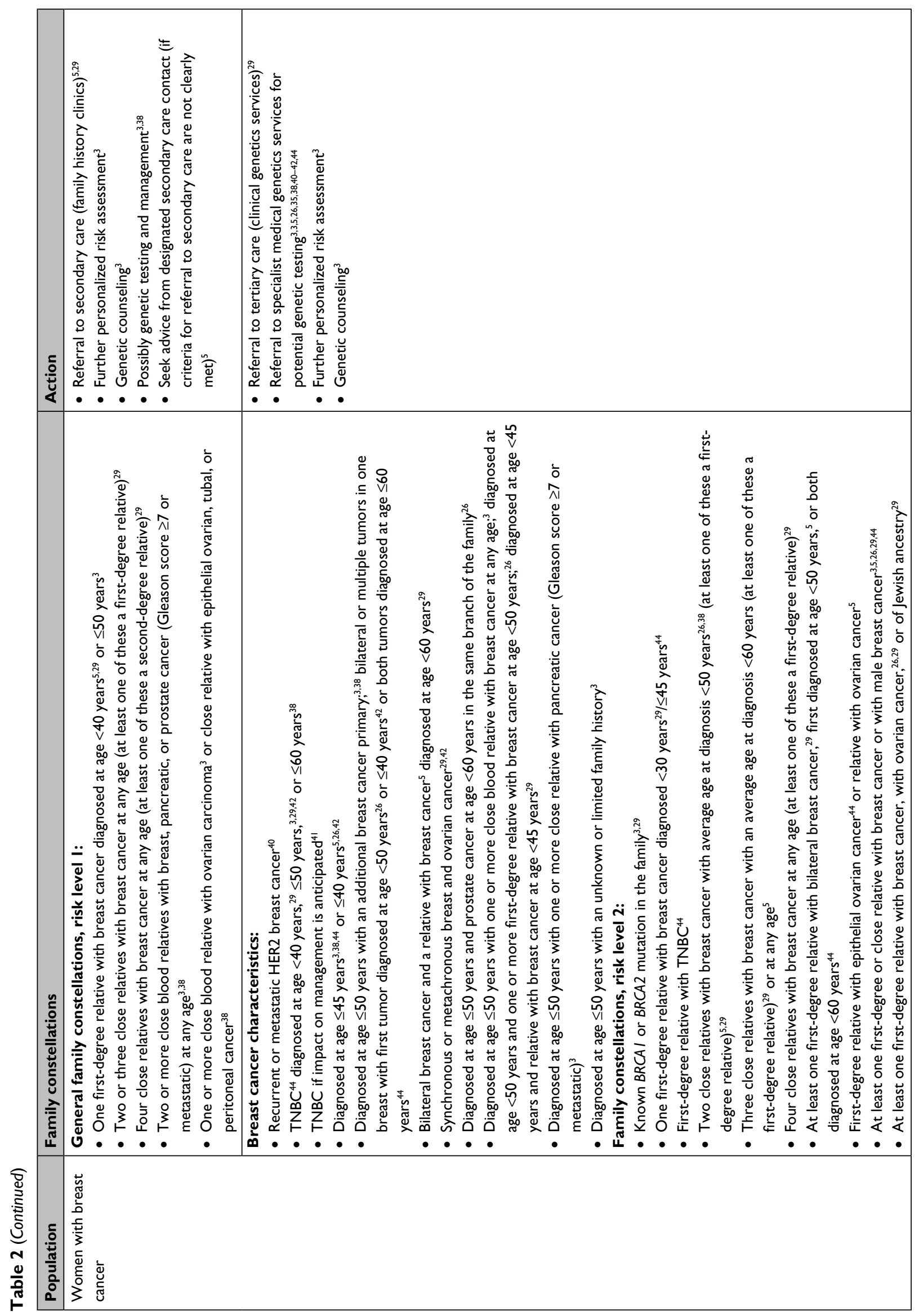




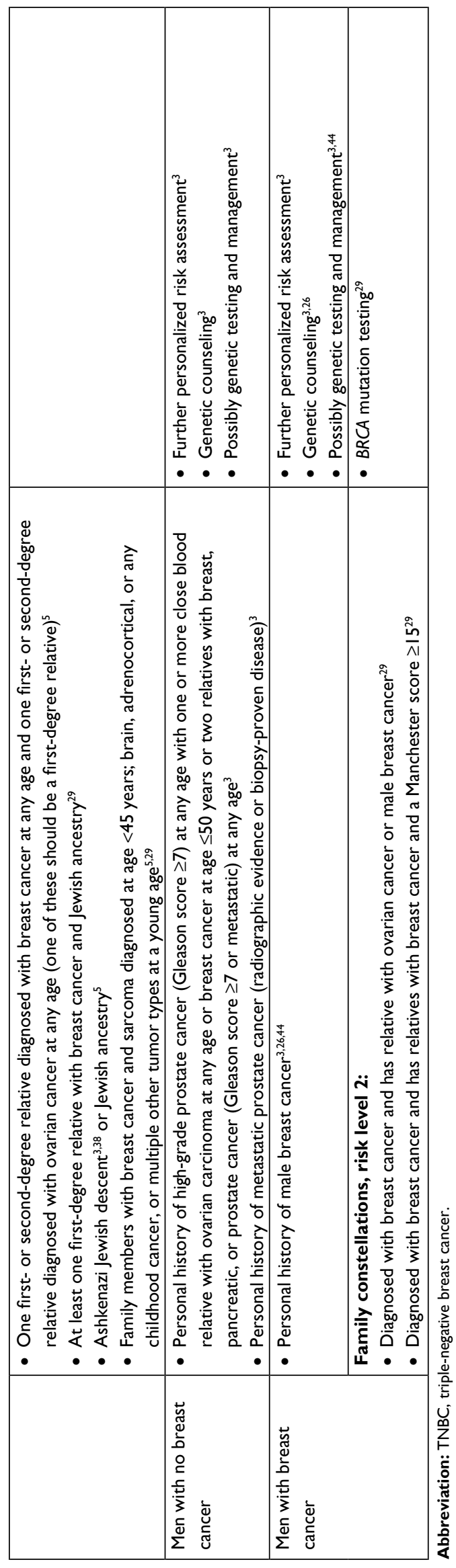

participate in high-risk follow-up clinics. The UK Institute of Cancer Research (ICR) Protocol $32015^{46}$ emphasized that women with a $B R C A$ mutation may be eligible for surveillance in research studies. The Dutch IKNL $2012^{26}$ guideline cautioned against the elevated risk of radiation-induced tumors with mammography in young women with a $B R C A$ mutation. The UK NICE (CG14 and CG41 updates) $2017^{5}$ guideline recommended that women with a $B R C A$ mutation deciding against risk-reducing mastectomy should be surveyed according to their level of risk.

Three guidelines ${ }^{3,4,42}$ indicated that men with a $B R C A$ mutation should undergo annual breast examination starting at age 35 years. However, the ESMO Prevention and Screening $2016^{4}$ guideline commented that there was no evidence to support routine breast imaging in men. The UK ICR Protocol $32015^{46}$ guideline and the German Arbeitsgemeinschaft Gynäkologische Onkologie (AGO) $2017^{41}$ guideline stated that no specific surveillance for men with $B R C A$ mutation is recommended, other than "watchful waiting".

There were no breast screening recommendations specifically relating to black/African populations, Ashkenazi Jews, or patients with HR-positive/HER2-negative disease and TNBC.

\section{Recommendations for the treatment of $B R C A B C$}

Eight guidelines made recommendations for the treatment of individuals with $B R C A$ mutation or those with a strong familial risk of developing $\mathrm{BC}$. These included two pan-European guidelines, ${ }^{21,22}$ two from Germany, ${ }^{23,41}$ two from the USA, ${ }^{40,48}$ one from Australia, ${ }^{19}$ and one from Spain. ${ }^{42} \mathrm{~A}$ summary of guideline recommendations for treatment is shown in Table 3.

None of the guidelines reported treatment pathway algorithms specific to the treatment of patients with $B R C A$ $\mathrm{BC}$ or those with a strong familial $\mathrm{BC}$ risk. Two guidelines made general treatment recommendations, and each stated that indications for treatment should not be influenced by BRCA status (Cancer Australia 2014: ${ }^{19}$ Arbeitsgemeinschaft der Wissenschaftlichen Medizinischen Fachgesellschaften [AWMF] Registry 2012). ${ }^{23}$

Three guidelines suggested platinum therapy as an option for treatment, specifically as a neoadjuvant therapy (AWMF Registry 2012), ${ }^{23}$ especially for metastatic $B R C A$-mutated BC (Sociedad Española de Oncología Médica 2015), ${ }^{42}$ and in young women (age $<40$ years) with $B R C A$-mutated $\mathrm{BC}$ (ESO-ESMO BCY3 2017). ${ }^{21}$ The ESO-ESMO ABC $32017^{22}$ guideline stated that "carboplatin is an important treatment option with a favorable toxicity profile regardless of $B R C A$ 


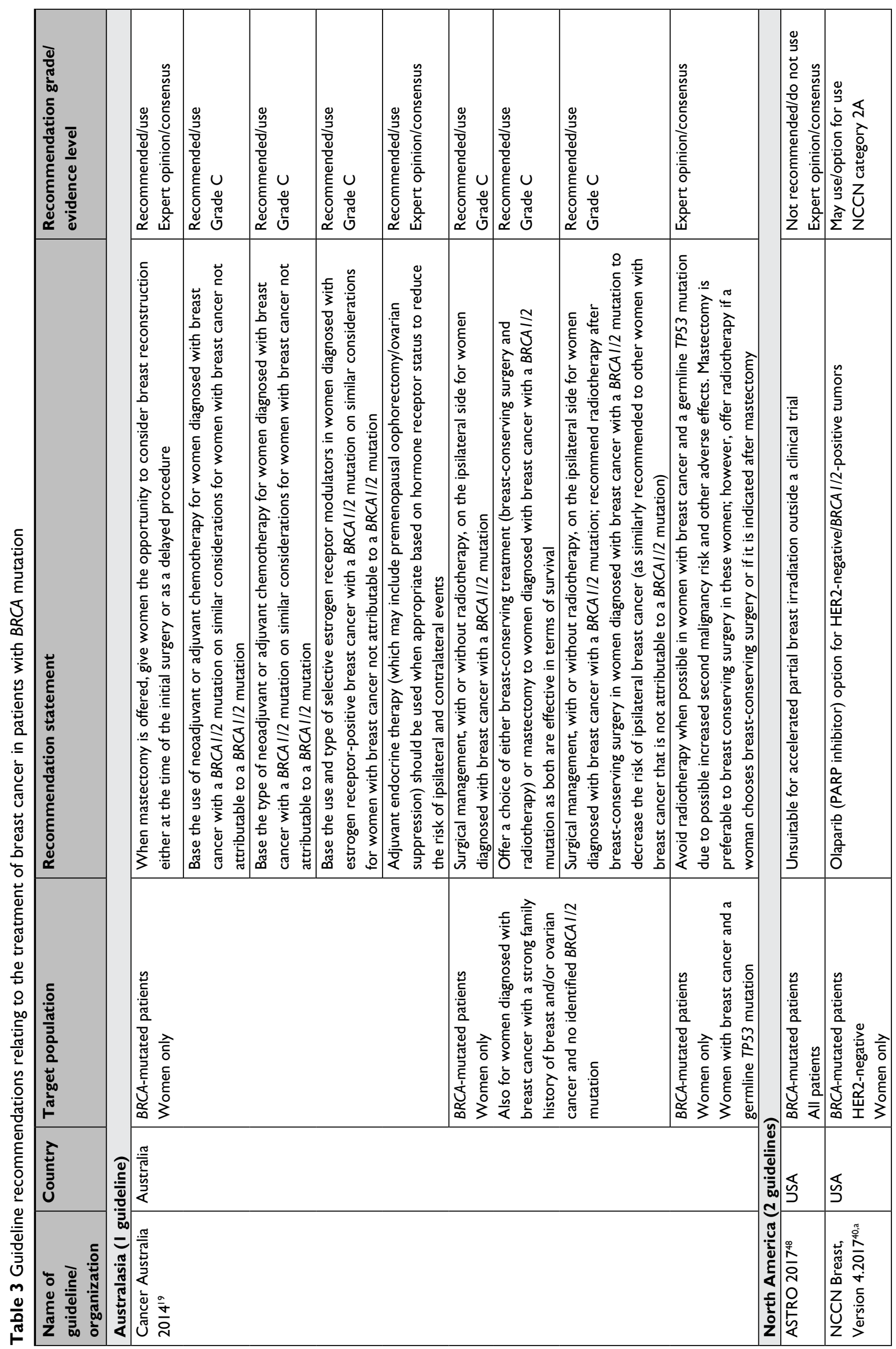




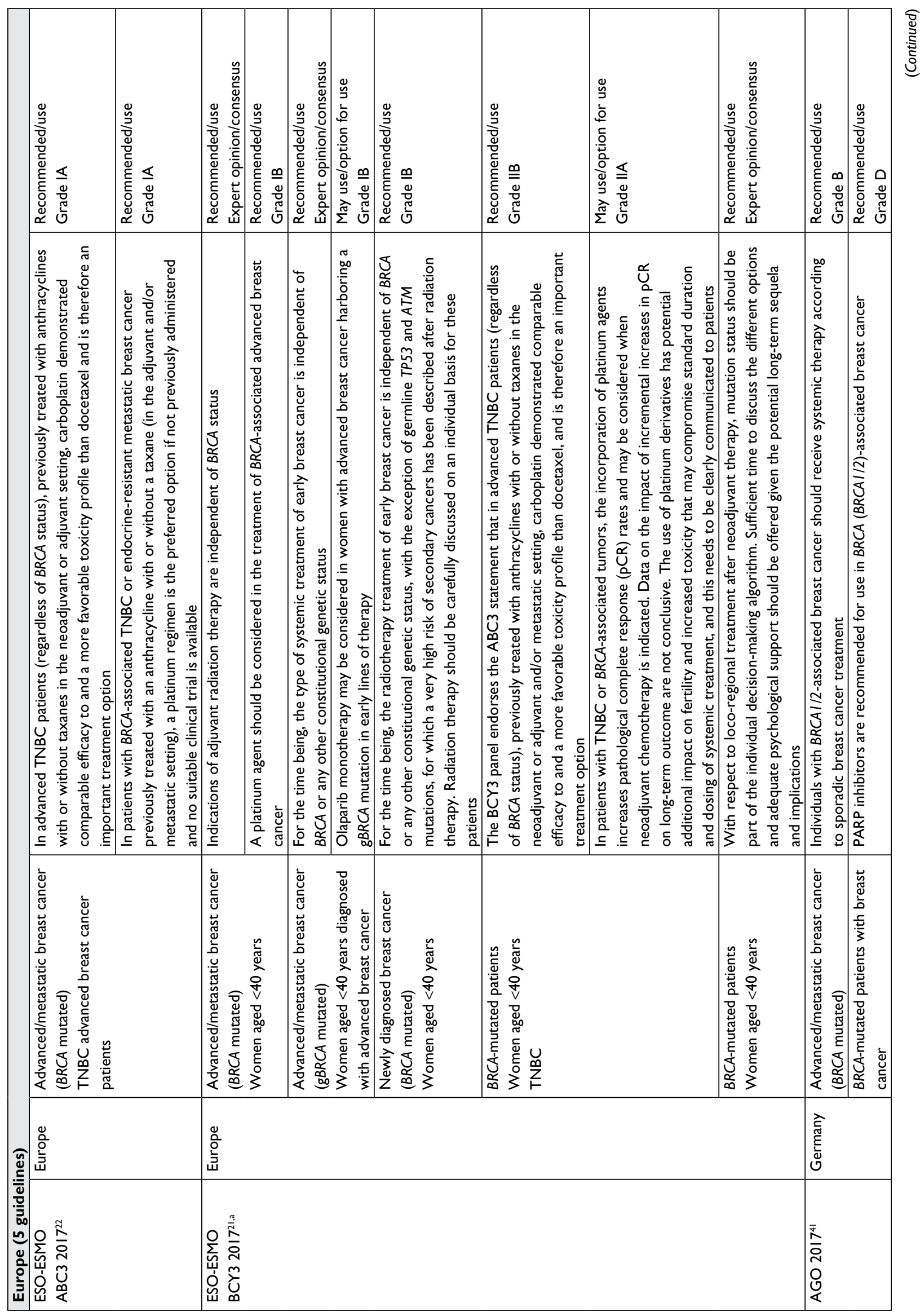




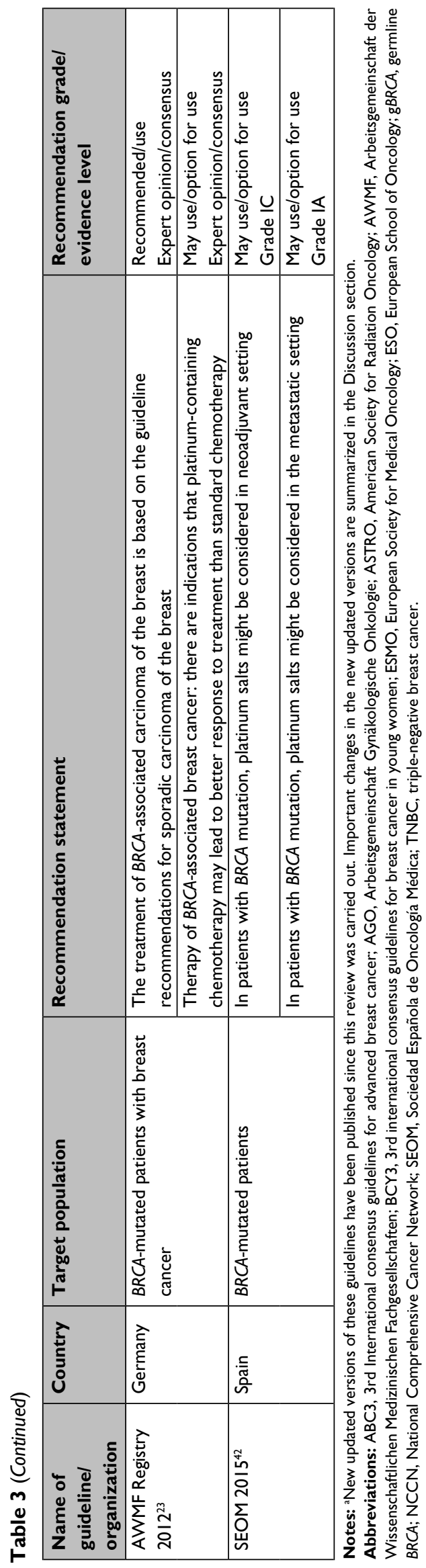

status, specifically for TNBC patients with $\mathrm{ABC}$ who had been previously treated with anthracyclines with or without taxanes in the neoadjuvant or adjuvant and/or metastatic setting". ${ }^{22}$ The UK LCA $2016^{29}$ guideline suggested that women with $B R C A 1 / 2$ mutations should be informed about the possibility of taking part in clinical trials, eg, on the therapeutic effects of PARP inhibitors in women with $B R C A$ mutations and breast or ovarian cancer. Two guidelines suggested the use of olaparib as a treatment option for BRCA-mutated HER2-negative BC (NCCN Breast Cancer Evidence Blocks, version 4.2017$)^{40}$ and for women with $\mathrm{g} B R C A$ (age $<40$ years) diagnosed with ABC (ESO-ESMO BCY3 2017). ${ }^{21}$ The AGO 2017 guidelines also recommended the use of PARP inhibitors in BRCA mutation (BRCA1/2) BC.41

No recommendations were made specifically about the treatment of BRCA-mutated $\mathrm{BC}$ in men, blacks/Africans, Ashkenazi Jews, and patients with HR-positive/HER2negative BC. With respect to therapy, the European ESOESMO BCY3 $2017^{21}$ guidelines recommended (based on expert opinion or consensus) that the therapeutic implications of somatic BRCA1/2 mutations in breast tumors of women aged $<40$ years be further explored within a research setting and not be currently applied for decision-making in routine clinical practice.

\section{Discussion}

To the best of our knowledge, this is the first systematic review to summarize international guidelines and recommendations for the genetic screening, diagnosis, genetic counseling, and treatment of $B R C A$-mutated $\mathrm{BC}$. By adhering to a rigorous systematic review methodology and focusing on guidelines published in the last 10-year period (1 January 2007 up to 16 February 2018), the quality, differences, and similarities across international guidelines regarding the management of $B R C A$-mutated $\mathrm{BC}$ were evaluated. Across guidelines reporting recommendations on $B R C A 1 / 2$ mutation testing and genetic counseling, there was an emphasis on the importance of genetic counseling both before and after testing in order for patients to make informed decisions about their care. Genetic counseling was identified as important prior to $\mathrm{BC}$ risk-reduction procedures. This is further supported by recent research suggesting a need for more innovative approaches to integrate genetic counseling into clinical practice in the modern era of increased use of multigene panel testing. ${ }^{49}$ Genetic counseling and genetic test results should also be incorporated into management of $\mathrm{BC}$ patients when making decisions about the type of surgery, consideration of radiotherapy, and the value of systemic therapy in neoadju- 
vant and advanced settings (including response to platinumbased chemotherapy and PARP inhibitors). ${ }^{50-52}$

The results of this study are limited by the inclusion dates of the systematic review. Since we carried out this review, updated guidelines have become available from the US NCCN (NCCN Breast Cancer, Version 1.2018 ${ }^{31}$ and NCCN Genetic/Familial High-Risk Assessment: Breast and Ovarian, Version 2, 2019), ${ }^{53}$ AGO (AGO 2018), ${ }^{54}$ and ESMO (ABC4). ${ }^{55}$ The NCCN guidelines have further broadened their recommendations regarding genetic screening criteria for $B R C A$ mutation. The recommendation within the NCCN Breast Cancer Evidence Blocks, Version 4.2017, ${ }^{40}$ that patients with "HER2-BC eligible for single-agent therapy are eligible for $B R C A 1 / 2$ testing", as identified in our review, has been strengthened in the updated NCCN Breast Cancer, Version $1.2018,{ }^{31}$ to recommend that $B R C A 1 / 2$ testing should be "strongly considered". The recently updated NCCN Genetic/Familial High-Risk Assessment: Breast and Ovarian, Version $2.2019^{53}$ recommends that "regardless of family history, some individuals with a $B R C A$-related cancer may benefit from genetic testing to determine eligibility for targeted treatment", including PARP inhibitors for metastatic HER2-BC. ${ }^{53}$ The guidelines also state that tumor-only profiling may detect $B R C A$ mutation of somatic or germline origin and that although "germline origin can sometimes be inferred with a high degree of confidence (eg, founder pathogenic/ likely pathogenic variants in $B R C A 1 / 2$ ), confirmatory testing is indicated for pathogenic/likely pathogenic variants with a reasonable clinical suspicion of being germline". ${ }^{53}$ However, the guidelines emphasize that "clinically indicated germline testing is still appropriate for patients meeting testing guidelines regardless of tumor profiling results", as "the absence of reported pathogenic/likely pathogenic variants in a particular gene does not rule out the possibility of germline pathogenic/likely pathogenic variant in that gene" ${ }^{53}$ The ESMO ABC4 guidelines state that "in the ABC setting, results from genetic testing may have therapeutic implications and should therefore be considered as early as possible" and "germline mutations in $B R C A 1 / 2$ have proven clinical utility and therapeutic impact". ${ }^{55}$ A recent review by Tung et al also discussed the future potential utility regarding the identification of somatic or germline $B R C A$ mutation in informing the optimal management of BC. ${ }^{50}$

Another key area of interest in the majority of guidelines in our review was the identification of appropriate individuals to undergo $B R C A 1 / 2$ mutation testing. The guidelines, regardless of geography, were in agreement that genetic testing for $B R C A$ mutations should be discussed with patients and offered to those who want to undergo testing. The identification of individuals was based on familial background and personal BC (and other cancer) history. We found some differences regarding types of individuals, but there was consensus about those with key indicators, such as Ashkenazi Jewish heritage and familial/personal histories of cancer, including male BC and TNBC.

Although all guidelines advised targeting specific individuals for $B R C A$ testing, recent research supports growing evidence for the expansion of $B R C A$ testing to a broader range of individuals, if not to the general population. ${ }^{56}$ Research has indicated that using the traditional familial and risk-based approach may miss a significant number of individuals with a $B R C A$ mutation. ${ }^{57-59}$ In addition, the multiple criteria and complexity of major guidelines, including those from the NCCN and the American Society of Clinical Oncology, make them difficult to use and implement systematically in real-world clinical practice. Multiple published international studies have shown that consequently, fewer patients have been offered genetic counseling and/or $B R C A$ testing, even while fulfilling their respective country-specific guideline criteria. ${ }^{60-62}$

A recent cost-effectiveness analysis ${ }^{63}$ of population-based mutation screening for $B R C A 1 / 2$ and other known high/ moderate penetrance genes ( $R A D 51 C, R A D 51 D, B R I P 1$, and $P A L B 2)$ in unselected populations of US and UK women concluded that population-based high/moderate penetrance gene (including $B R C A 1 / 2$ ) testing is more cost-effective than any system of identifying individuals through clinical criteria or familial history. Compared with clinical criteria and familial history-based $B R C A 1 / 2$ testing in a decision-analytic model, population-based testing also led to increases in the number of $\mathrm{BC}$ cases prevented (1.86\% in UK women and $1.91 \%$ in US women) and $\mathrm{BC}$ deaths prevented (523 per million women in the UK and 367 per million women in the USA). Other earlier research in a population of healthy Australian women $^{64}$ similarly suggested that a general population-based screening program rather than a targeted high-risk approach may be favorable.

The type of $B R C A$ test will affect not only how accurate the findings are, but also how cost-effective a screening program is likely to be. A recent worldwide survey of testing laboratories found wide variations in the types of technologies used for BRCA1/2 testing. ${ }^{65}$ Other researchers have identified that multi-gene sequencing approaches are preferable to $B R C A 1 / 2$-only testing for patients with BC. ${ }^{66}$ Only three included guidelines offered recommendations on which type of $B R C A$ testing to use, indicating the test should have as close to $100 \%$ sensitivity as possible and needs to 
search the whole gene, including testing for large genomic rearrangements and coding alterations. ${ }^{3,5,21}$ The ESO-ESMO BCY3 guidelines stated that "when a hereditary cancer syndrome is suspected and a mutation in $B R C A 1 / 2$ has not been identified, multigene panel testing may be considered". ${ }^{21}$ In addition, the updated ESO-ESMO ABC4 $2018^{55}$ guidelines stated that "multigene panels, such as those obtained using next-generation sequencing (NGS) or other technology on tumor DNA have not yet proven beneficial in clinical trials for $\mathrm{ABC}$, their impact on outcome remains undefined and should not be used in routine clinical practice". The ESO-ESMO ABC4 2018 guidelines ${ }^{55}$ further indicate that for patients who are suitable to participate in clinical trials, NGS testing may be used in the context of prospective molecular triage programs for patient selection. Specific tests (as distinguished from broad mutation profiles) may play a greater role in the future as the medicines with which they are associated gain regulatory approval. Researchers have also investigated which, if any, $B R C A$ genetic testing programs are ready for implementation in health care settings. A systematic review ${ }^{67}$ assessed economic evaluations and found that cost-effectiveness was highly sensitive to the cost of $B R C A 1 / 2$ testing. As our understanding develops on how to improve screening, increased accuracy and lower pricing of tests may make screening the wider population of otherwise healthy women more cost-effective.

It should be noted that the guidelines identified in our review provided limited recommendations on the treatment options available for $B R C A \mathrm{ABC}$, and no treatment algorithms or pathways were reported. Several guidelines suggested potential benefits from platinum therapy, ${ }^{21,23,42}$ and the recent US NCCN Breast Cancer, Version 4.2017 guidelines also recommended the recently approved PARP inhibitor olaparib as an option for the treatment of HER2-negative, BRCA1/2-mutated tumors. ${ }^{40}$ The AGO 2017 guidelines in Germany also recommended the use of PARP inhibitors for the treatment of BRCA-mutation associated BC. ${ }^{41}$ The

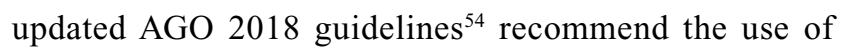
olaparib in patients with HER2-gBRCA mutation, including those who are estrogen receptor-positive and those with TNBC. The ESMO ABC4 guidelines ${ }^{55}$ also now highlight the use of PARP inhibitors (including olaparib and talazoparib) as a "reasonable treatment option for patients with $B R C A$ associated TNBC or luminal (after progression on endocrine therapy) $\mathrm{ABC}$, previously treated with an anthracycline with/ without a taxane (in the adjuvant and/or metastatic setting)"; "the tolerability of these agents when given as monotherapy, the chemotherapy-free approach with improved quality of life makes it an attractive options for $B R C A$-related $\mathrm{ABC}$ " ${ }^{55}$ Given the arrival of this new group of $\mathrm{g} B R C A$-targeting drugs, it seems likely that all future guidelines will need to consider this as a treatment option.

With the differences in the care of patients compounded by the evolution of international guidelines across genetic screening, diagnosis, genetic counseling, and treatment of $B R C A$-mutated $\mathrm{BC}$, there is a growing need to establish a translational research infrastructure ${ }^{68}$ that aims to integrate evidence-based guidelines into clinical care while assessing the validity and utility on health outcomes among BC patients. While greater consensus and guideline harmonization across geographies would optimize the identification and management of $\mathrm{BC}$ patients with $B R C A$ mutation, other potential barriers should also be considered. Targeted continuing medical education will be vital in improving the communication, knowledge, awareness, and guidelineconcordance among clinicians and public health professionals regarding population-based $B R C A$ screening. ${ }^{11-13}$ To improve patients' experience and utility of genetic information, ${ }^{69}$ further understanding of the potential barriers regarding patients' acceptance of $B R C A$ testing, perceived undefined changes in quality of life, and unknown clinical utility is warranted.

\section{Evidence gaps identified by the review}

Given issues highlighted in this review regarding the methodologies used to develop guidelines, there is a need for future guidelines to follow recognized methodologies and use tools developed by the Grading of Recommendations Assessment, Development and Evaluation ${ }^{70}$ working group to clearly assess and describe the strength of any recommendations. In addition, guideline reporting should adhere to the recommendations of the Reporting Tool for Practice Guidelines in Health Care (RIGHT) statement ${ }^{71}$ and the AGREE Reporting Checklist, a tool to improve the reporting of clinical practice guidelines. ${ }^{16}$

In addition, the guidelines included in our review identified a number of areas where evidence was poor and/ or lacking and where further research is required. Recent UK guidelines (NICE [CG14 and CG41 update] 2017) ${ }^{5}$ highlighted that further investigations are required into the benefits and harms of creating rapid access to genetic testing for people with newly diagnosed BC, including optimum models for service delivery and organization, clinical and cost-effectiveness of such a change, uptake outcomes, and patient experience within different geographies and settings. ${ }^{5}$ NICE also suggested research is required into which members of a multidisciplinary team should or could discuss fast-track 
testing with patients and that this should form part of a trial of fast-track genetic testing in patients with familial risk and newly diagnosed BC. Additionally, among those women who are identified as $B R C A$ mutation carriers, further research should compare psychosocial and clinical outcomes in women who choose or do not choose to have risk-reduction surgery. ${ }^{5}$ ESO-ESMO BYC3 guidelines highlighted that the therapeutic implications of somatic BRCA1/2 mutations in breast tumors in women aged $<40$ years should be further explored within a research setting before they can be used in routine clinical practice. ${ }^{21}$ This is also reinforced in the ABC setting within the new ESMO ABC4 guidelines. ${ }^{55}$ Our review also showed that there were limited recommendations (and in some cases conflicting advice across geographies) relating specifically to the care of men with $\mathrm{g} B R C A$ mutations, suggesting that this also requires further investigation and consensus.

\section{Conclusion}

This systematic review reports a broad, comprehensive summary of the latest international guideline recommendations for the genetic screening, diagnosis, genetic counseling, and treatment of $B R C A$-mutated BC. Recent recommendations within treatment guidelines for $\mathrm{g} B R C A$ ABC highlight the promise of platinum-based chemotherapies and PARP inhibitors. Identifying individuals who carry $B R C A$ mutations is therefore becoming increasingly important. Although a number of guidelines across various countries focus on identifying such high-risk individuals, the most recent guidelines adopt broader criteria regardless of family history. This supports the growing evidence within the literature suggesting that clinical criteria/family history criteria may miss individuals with $B R C A$ mutations, with some indicating that $B R C A$ testing should be expanded to the broader population. In order to ensure that patients are able to make a fully informed decision to undergo genetic $B R C A$ testing, the guidelines also stress the importance of providing genetic counseling before and after $B R C A$ testing.

Future clinical guidelines and recommendations should follow methodological guidance for their development and adhere to specific reporting tools. Current gaps within the evidence suggest that recommendations are required specifically relating to genetic screening, counseling, and treatment of black/African populations at high risk of $B R C A$ mutations. In addition, greater consensus and harmonization across geographies would optimize identification and management of patients with $B R C A$-mutated $\mathrm{BC}$.

\section{Acknowledgments}

Editorial and medical writing support was provided by Edwin Thrower, PhD, and Paula Stuckart of Ashfield Healthcare Communications, Middletown, CT, USA, and was funded by Pfizer Inc. This study was sponsored by Pfizer Inc. This work has been previously presented as an abstract and poster at the European Society for Medical Oncology (ESMO) 2018 Congress, 19th to 23rd October 2018, Munich, Germany.

\section{Disclosure}

CF, DF, and SdK are employees of Kleijnen Systematic Reviews Ltd. who were paid consultants to Pfizer Inc. in connection with the development of this manuscript. RGWQ is an employee of Pfizer Inc. The authors report no other conflicts of interest with respect to this work.

\section{References}

1. Engel C, Fischer C. Breast cancer risks and risk prediction models. Breast Care. 2015;10(1):7-12.

2. Greenup R, Buchanan A, Lorizio W, et al. Prevalence of BRCA mutations among women with triple-negative breast cancer (TNBC) in a genetic counseling cohort. Ann Surg Oncol. 2013;20(10):3254-3258.

3. National Comprehensive Cancer Network. Genetic/familial high-risk assessment: breast and ovarian. Version 1.2018, October 3, 2017 NCCN Clinical Practice Guidelines in Oncology (NCCN Guidelines) 2017. Available from: https://www.nccn.org/. Accessed December 15, 2017.

4. Paluch-Shimon S, Cardoso F, Sessa C, et al. Prevention and screening in BRCA mutation carriers and other breast/ovarian hereditary cancer syndromes: ESMO clinical practice guidelines for cancer prevention and screening. Ann Oncol. 2016;27(Suppl 5):v103-v110.

5. National Institute for Health and Care Excellence [homepage on the Internet]. Familial breast cancer: classification, care and managing breast cancer and related risks in people with a family history of breast cancer. NICE clinical guideline CG164; 2013. Available from: nice.org. uk/guidance/cg164. Accessed November 30, 2017.

6. Cragun D, Weidner A, Lewis C, et al. Racial disparities in $B R C A$ testing and cancer risk management across a population-based sample of young breast cancer survivors. Cancer. 2017;123(13):2497-2505.

7. Litton JK, Rugo HS, Ettl J, et al. Talazoparib in patients with advanced breast cancer and a germline BRCA mutation. $N$ Engl $J$ Med. 2018;379(8):753-763.

8. Robson M, Im SA, Senkus E, et al. Olaparib for metastatic breast cancer in patients with a germline BRCA mutation. $N$ Engl J Med. 2017;377(6):523-533.

9. Tutt A, Tovey H, Cheang MCU, et al. Carboplatin in BRCA1/2-mutated and triple-negative breast cancer BRCAness subgroups: the TNT trial. Nat Med. 2018;24(5):628-637.

10. Livraghi L, Garber JE. PARP inhibitors in the management of breast cancer: current data and future prospects. BMC Med. 2015; 13(1): 188

11. Bellcross CA, Kolor K, Goddard KA, Coates RJ, Reyes M, Khoury MJ. Awareness and utilization of BRCA1/2 testing among U.S. primary care physicians. Am J Prev Med. 2011;40(1):61-66.

12. Marzuillo C, De Vito C, Boccia S, et al. Knowledge, attitudes and behavior of physicians regarding predictive genetic tests for breast and colorectal cancer. Prev Med. 2013;57(5):477-482.

13. Marzuillo C, De Vito C, D'Addario M, et al. Are public health professionals prepared for public health genomics? A cross-sectional survey in Italy. BMC Health Serv Res. 2014;14(1):239. 
14. Higgins JPT, Green S, editors. Cochrane Handbook for Systematic Reviews of Interventions [Internet]. Version 5.1.0 [updated March 2011]: The Cochrane Collaboration; 2011. Available from: http:// handbook-5-1.cochrane.org/. Accessed March 23, 2011.

15. Centre for Reviews and Dissemination [homepage on the Internet]. Systematic Reviews: CRD's guidance for undertaking reviews in health care; 2009. Available from: http://www.york.ac.uk/inst/crd/ SysRev/!SSL!/WebHelp/SysRev3.htm. Accessed December 1, 2018.

16. $\mathrm{Km} \mathrm{BM}$, Browman GP, et al. Agree II: advancing Guideline Development, reporting and evaluation in healthcare. CAMJ. 2010;182(18): E839-E842.

17. Lee CH, Dershaw DD, Kopans D, et al. Breast cancer screening with imaging: recommendations from the Society of breast imaging and the ACR on the use of mammography, breast MRI, breast ultrasound, and other technologies for the detection of clinically occult breast cancer. J Am Coll Radiol. 2010;7(1):18-27.

18. National Comprehensive Cancer Network [Internet]. Breast Cancer Risk Reduction: NCCN Evidence Blocks. Version 1.2018, February 2, 2018. Fort Washington (PA): NCCN; 2018.

19. Cancer Australia [Internet]. Recommendations for the management of early breast cancer in women with an identified BRCA1 or BRCA2 gene mutation or at high risk of a gene mutation; 2014. Available from: http:// guidelines.canceraustralia.gov.au/guidelines/gene_mutation/index.php. Accessed January 5, 2018.

20. Taira N, Arai M, Ikeda M, et al. The Japanese Breast Cancer Society clinical practice guidelines for epidemiology and prevention of breast cancer, 2015 edition. Breast Cancer. 2016;23(3):343-356.

21. Paluch-Shimon S, Pagani O, Partridge AH, et al. ESO-ESMO 3rd international consensus guidelines for breast cancer in young women (BCY3). Breast. 2017;35:203-217.

22. Cardoso F, Costa A, Senkus E, et al. 3rd ESO-ESMO international consensus guidelines for advanced breast cancer (ABC 3). Ann Oncol. 2017;28(12):3111-3133.

23. Kreienberg R, Albert U-S, Follmann M, Kopp I, Kühn T, Wöckel A. Interdisciplinary GoR level III guidelines for the diagnosis, therapy and follow-up care of breast cancer. Geburtshilfe Frauenheilkd. 2013;73(6): 556-583.

24. Mainiero MB, Moy L, Baron P, et al. ACR appropriateness criteria breast cancer screening. J Am Coll Radiol. 2017;14(11):S383-S390.

25. Cancer Care Ontario [homepage on the Internet]. Magnetic resonance imaging screening of women at high risk for breast cancer; 2012. Available from: https://www.cancercareontario.ca/en/file/17606/ download?token=6D-cb8xw. Accessed November 30, 2017.

26. Integraal Kankercentrum Nederland. Mammacarcinoom. National evidence based guideline; 2012. Available from: http://www.oncoline. nl/mammacarcinoom. Accessed November 29, 2017.

27. National Cancer Control Programme [Internet]. Diagnosis, staging and treatment of patients with breast cancer: national clinical guideline no. 7; 2015. Available from: https://www.hse.ie/eng/services/list/5/cancer/ profinfo/guidelines/breast/breastguideline.pdf. Accessed November 30, 2017.

28. Wright FC, Look Hong NJ, Quan ML, et al. Indications for contralateral prophylactic mastectomy: a consensus statement using modified Delphi methodology. Ann Surg. 2018;267(2):271-279.

29. London Cancer Alliance [Internet]. LCA breast cancer clinical guidelines; 2013 (updated March 2016). Available from: http://rmpartners. cancervanguard.nhs.uk/wp-content/uploads/2017/03/lca-breast-cancerclinical-guidelines-october-2013-updated-march-2016-.pdf. Accessed November 30, 2017.

30. National Comprehensive Cancer Network [Internet]. Breast cancer screening and diagnosis (version 1. 2017, June 2, 2017). NCCN Clinical Practice Guidelines in Oncology (NCCN guidelines); 2017. Available from: https://www.nccn.org. Accessed December 20, 2017.

31. National Comprehensive Cancer Network [Internet]. Breast cancer (version 1.2018, March 20, 2018); 2018; 209. Available from: https:// www.nccn.org/. Accessed April 10, 2018.
32. National Institute for Health and Care Excellence. Olaparib for maintenance treatment of relapsed, platinum-sensitive, BRCA mutation-positive ovarian, fallopian tube ad peritoneal cancer after resposne to second-line or subsequent plantinum-based chemotherapy [Internet]; 2016. Available from: https://www.guideline.gov/ summaries/downloadcontent/ngc-10895? contentType=pdf. Accessed November 30, 2017.

33. Runowicz CD, Leach CR, Henry NL, et al. American cancer Society/ American Society of clinical oncology breast cancer survivorship care guideline. CA Cancer J Clin. 2016;66(1):43-73.

34. Senkus E, Kyriakides S, Ohno S, et al. Primary breast cancer: ESMO clinical practice guidelines for diagnosis, treatment and follow-up. Ann Oncol. 2015;26(Suppl 5):v8-v30.

35. Toward Optimized Practice (TOP) Working Group for breast cancer screening. Breast cancer screening: clinical practice guideline; 2013. Available from: http://www.topalbertadoctors.org/download/243/ breast_cancer_guideline.pdf?_20150423045720. Accessed November 30, 2017.

36. Hampel H, Bennett RL, Buchanan A, Pearlman R, Wiesner GL, Guideline Development Group, American College of Medical Genetics and Genomics Professional Practice and Guidelines Committee and National Society of Genetic Counselors Practice Guidelines Committee. A practice guideline from the American College of Medical Genetics and Genomics and the National Society of Genetic Counselors: referral indications for cancer predisposition assessment. Genet Med. 2015;17(1):70-87.

37. Runowicz CD, Leach CR, Henry NL, et al. American Cancer Society/ American Society of Clinical Oncology Breast Cancer Survivorship Care Guideline. J Clin Oncol. 2016;34(6):611-635.

38. Lancaster JM, Powell CB, Chen LM, Richardson DL; SGO Clinical Practice Committee. Society of Gynecologic Oncology statement on risk assessment for inherited gynecologic cancer predispositions. Gynecol Oncol. 2015;136(1):3-7.

39. U.S. Preventive Services Task Force [Internet]. Evidence summary. Other supporting document for BRCA-related cancer: risk assessment, genetic counseling, and genetic testing; 2013. Available from: https:// www.uspreventiveservicestaskforce.org/Page/Document/evidencesummary $17 /$ brca-related-cancer-risk-assessment-genetic-counselingand-genetic-testing. Accessed December 5, 2017.

40. National Comprehensive Cancer Network [Internet]. Breast cancer: NCCN evidence blocks (version 4.2017, February 9, 2018); 2018. Available from: https://www.nccn.org/professionals/physician_gls/pdf/ breast_blocks.pdf. Accessed February 16, 2018.

41. Arbeitsgemeinschaft Gynäkologische Onkologie E.V [Internet]. Diagnosis and treatment of patients with primary and metastatic breast cancer; 2017. Available from: https://www.ago-online.de/fileadmin/ downloads/leitlinien/mamma/2017-03/AGO_englisch/PDF_Gesamtdatei_englisch/Updated\%20Guidelines_2017.pdf. Accessed December 19, 2017.

42. Llort G, Chirivella I, Morales R, et al. SEOM clinical guidelines in Hereditary Breast and ovarian cancer. Clin Transl Oncol. 2015;17(12):956-961.

43. Healthcare Improvement Scotland [Internet]. Familial breast cancer report; 2014. Available from: http://www.healthcareimprovementscotland.org/his/idoc .ashx?docid $=47 \mathrm{~b} 6 \mathrm{cdaa}-175 \mathrm{e}-482 \mathrm{~b}-$ a564-6d68860b6d20\&version=-1. Accessed November 30, 2017.

44. The Royal Marsden NHS Foundation Trust [Internet]. Protocol 2: BRCA1 and BRCA2 mutation testing; 2017. Available from: https:// d1ijoxngr27nfi.cloudfront.net/default-document-library/protocol2-brca-mutation-testing.pdf?sfvrsn $=0$. Accessed November 30, 2017.

45. The Royal Marsden NHS Foundation Trust [Internet]. Protocol 1: management guidelines for unaffected women with a family history of breast and/or ovarian cancer; 2015. Available from: https://d1ijoxngr27nfi.cloudfront.net/research-divisions/protocol-1-mammographicsurveillance_20150209_v4.pdf?sfvrsn=2. Accessed November 30, 2017. 
46. The Royal Marsden NHS Foundation Trust [Internet]. Protocol 3: BRCA mutation carrier guidelines; 2015. Available from: https://d1ijoxngr27nfi. cloudfront.net/research-divisions/protocol-3-brca-mutation-carrier20150209-v4.pdf?sfvrsn=2. Accessed November 30, 2017.

47. The Royal College of Radiologists Faculty of Clinical Radiology [Internet]. Guidance on screening and symptomatic breast imaging; 2013 , 3rd ed. Available from: https://www.rcr.ac.uk/system/files/publication/ field_publication_files/BFCR(13)5_breast.pdf. Accessed December 1, 2017.

48. American Society for Radiation Oncology. Accelerated Partial Breast Irradiation: Update of an ASTRO Evidence-based Consensus Statement. Alington (VA): Practical Radiation Oncology; 2017.

49. Katz SJ, Ward KC, Hamilton AS, et al. Gaps in receipt of clinically indicated genetic counseling after diagnosis of breast cancer. J Clin Oncol. 2018;36(12):1218-1224.

50. Tung NM, Garber JE. BRCA1/2 testing: therapeutic implications for breast cancer management. Br J Cancer. 2018;119(2):141-152.

51. Daly MB, Pilarski R, Berry M, et al. NCCN Guidelines Insights: Genetic/Familial High-Risk Assessment. Breast and Ovarian, Version 2.2017. J Natl Compar Canc Netw. 2017;15(1):9-20.

52. Byrski T, Huzarski T, Dent R, et al. Pathologic complete response to neoadjuvant cisplatin in BRCA1-positive breast cancer patients. Breast Cancer Res Treat. 2014;147(2):401-405.

53. National Comprehensive Cancer Network [Internet]. Genetic/familial high-risk assessment: breast and ovarian. Version 2.2019, July 30); 2018. Available from: https:/www.nccn.org/professionals/physician_gls/pdf/ genetics_screening.pdf. Accessed August 3, 2018.

54. E.V. AGO. Diagnosis and treatment of patients with primary and metastatic breast cancer. Taufkirchen, AGO; 2018. Available from: https:// www.ago-online.de/fileadmin/downloads/leitlinien/mamma/2018-03/ EN/Gesamt_PDF_Englisch/Updated_Guidelines_2018.pdf. Accessed January 18, 2018.

55. Cardoso F, Senkus E, Costa A, et al. 4th ESO-ESMO International Consensus Guidelines for Advanced Breast Cancer (ABC 4). Ann Oncol. 2018;29:1634-1657.

56. Rizk C [Internet]. Researchers Debate Merits of Population-Wide Genetic Testing at AARC. New York: GenomeWeb; 2017. Available from: https://www.genomeweb.com/genetic-research/researchersdebate-merits-population-wide-genetic-testing-aacr\#.W5wRSflKiUk. Accessed June 26, 2018.

57. Gabai-Kapara E, Lahad A, Kaufman B, et al. Population-based screening for breast and ovarian cancer risk due to BRCA1 and BRCA2. Proc Natl Acad Sci USA. 2014;111(39):14205-14210.

58. Metcalfe KA, Poll A, Royer R, et al. Screening for founder mutations in BRCA1 and BRCA2 in unselected Jewish women. J Clin Oncol. 2010;28(3):387-391.
59. Kang HH, Williams R, Leary J, et al. Evaluation of models to predict BRCA germline mutations. Br J Cancer. 2006;95(7):914-920.

60. Febbraro T, Robison K, Wilbur JS, et al. Adherence patterns to National Comprehensive Cancer Network (NCCN) guidelines for referral to cancer genetic professionals. Gynecol Oncol. 2015;138(1):109-114.

61. Nilsson MP, Winter C, Kristoffersson U, et al. Efficacy versus effectiveness of clinical genetic testing criteria for BRCA1 and BRCA2 hereditary mutations in incident breast cancer. Fam Cancer. 2017;16(2):187-193.

62. Tung N, Lin NU, Kidd J, et al. Frequency of germline mutations in 25 cancer susceptibility genes in a sequential series of patients with breast cancer. J Clin Oncol. 2016;34(13):1460-1468.

63. Manchanda R, Patel S, Gordeev VS, et al. Cost-effectiveness of population-based BRCA1, BRCA2, RAD51C, RAD51D, BRIP1, PALB2 mutation testing in unselected general population women. J Natl Cancer Inst. 2018;110(7):714-725.

64. Campbell IG, Rowley S, Devereux L, et al. Population genetic testing for breast cancer susceptibility. Paper presented at: San Antonio Breast Cancer Symposium; 5-9 December 2017; San Antonio (TX).

65. Toland AE, Forman A, Couch FJ, et al. Clinical testing of BRCA1 and BRCA2: a worldwide snapshot of technological practices. NPJ Genom Med. 2018;3(1):7.

66. Kurian AW, Ward KC, Hamilton AS, et al. Uptake, results, and outcomes of germline multiple-gene sequencing after diagnosis of breast cancer. JAMA Oncol. 2018;4(8):1066.

67. D'Andrea E, Marzuillo C, De Vito C, et al. Which BRCA genetic testing programs are ready for implementation in health care? A systematic review of economic evaluations. Genet Med. 2016;18(12):1171-1180.

68. Schully SD, Benedicto CB, Gillanders EM, Wang SS, Khoury MJ. Translational research in cancer genetics: the road less traveled. Public Health Genomics. 2011;14(1):1-8.

69. D'Andrea E, Lagerberg T, De Vito C, et al. Patient experience and utility of genetic information: a cross-sectional study among patients tested for cancer susceptibility and thrombophilia. Eur J Hum Genet. 2018;26(4):518-526.

70. Guyatt GH, Oxman AD, Schunemann HJ, Tugwell P, Knottnerus A. GRADE guidelines: a new series of articles in the Journal of Clinical Epidemiology. J Clin Epidemiol. 2011;64(4):380-382.

71. Chen Y, Yang K, Marušić A, et al. A reporting tool for practice guidelines in health care: the RIGHT statement. Ann Intern Med. 2017;166(2):128-132.
Cancer Management and Research

\section{Publish your work in this journal}

Cancer Management and Research is an international, peer-reviewed open access journal focusing on cancer research and the optimal use of preventative and integrated treatment interventions to achieve improved outcomes, enhanced survival and quality of life for the cancer patient. The manuscript management system is completely online and includes

\section{Dovepress}

a very quick and fair peer-review system, which is all easy to use. Visit http://www.dovepress.com/testimonials.php to read real quotes from published authors. 